mucous matrix, and are neither fasciculated nor laciniated at their ends; they are so very slender that the triplet is not sufficiently powerful to afford a proper examination. I was unable to perceive either dissepiments or sporangia. In no respect, except in their parallel arrangement, did the filaments correspond with Morren's description.

PLate IX. fig. 8. $a$, portion of stratum from Lough Neagh ; $b$, filament.

XXX.-On Trichites, a fossil yenus of Bivalve Mollusks. By JoHN LYCETT, Esq.*

[With a Plate.]

ThIs generic form is distributed over an extensive area both in this country and upon the continent; it occurs in more than one of the oolitic formations; the Cotteswold Hills more especially produce it abundantly; nevertheless it is almost entirely absent from the cabinets of English collectors; and if we examine that section of modern literature which professes to illustrate fossil conchology, our search will searcely be more successful or satisfactory. In both cases the defect may be accounted for by a difficulty almost insurmountable experienced in obtaining illustrative specimens in a condition perfect, or even approaching to perfect; fragments indeed are easily detached, but these alone do not convey any precise or adequate idea of the generic characters.

The shells are large, the very Titans of their period, sometimes extending to upwards of a yard across, of a thickness far surpassing that of bivalves generally, but of a structure peculiarly fragile (prismatic crystaliine), consisting of fibres closely arranged, placed perpendicularly to the surface and breaking readily in the direction of the fibres with any slight concussion; this is a serious obstacle to their separation, to which may be added, that the upper ragstone bed of the Inferior Oolite in which they most commonly occur is very hard and intractable in the nature of its fracture. In almost every open quarry of this rock, and more especially in the stratum called Trigonia grit, these thick fibrous masses may be noticed; more rarely also in the middle portion of the same formation and in the shelly beds of the Great Oolite. They have usually been referred to a gigantic species of Pinna, probably from a similarity of structure. The Cotteswolds have produced two species, which are distinct from another recorded from the Jura which will subsequently be noticed. Dr. Plott, the historian of Oxfordshire, appears to have been the first person who applied the tcrm Trichites to these shells. Woodward,

* Read to the Cotswold Naturalists' Club, Jan. 22, 1850. 
in his 'Catalogue of English Fossils,' 1725, part 2. p. 101, 102, 'De testis aliisque incerti generis,' mentions that Lhwyd sent a specimen of this genus from the Oolite of Bullington Green near Oxford, with the title "Trichites Plottii, Hist. Oxon. Veneris crines forsan Plinio," and adds the caustic remark, that these two writers, Dr. Plott of mere simplicity, and Lhwyd of design, "darken counsel by words without knowledge," Job. xxxviii. 2; he also records fragments in his collection from Risington and Birdlip Hill in Gloucestershire. The generic name was of course derived from its capillary or hair-like structure. Far from joining in the foregoing censure, we are rather disposed to respect the discrimination which recognized this obscure generic form in the earliest infancy of conchology. It was observed by Saussure in the Coralline Oolite of Mount Salève near Geneva, and described by Deluc in the first volume of the great work of Saussure on the Alps, p. 192, and figured in part 2. fig. 5, 6. This eminent naturalist ascertained some of the general features of the genus; the great thickness of the test, its fibrous structure, analogous, he observed, to that of Pinna, and its inequivalve form ; this latter character, he observed, compelled a generic separation, and he proposed to call it Pinnegene. Deluc seems to have been unacquainted with the prior claim of Lhwyd. Guettard and Defrance observed it in the oolitic rocks of Normandy; they regarded it as a distinct genus, but do not appear to have contributed anything material to its elucidation. The latter author's views are contained in an article contributed by him to the 'Dictionnaire des Sciences Naturelles,' tom. Iv. 1828.

Deshayes, in his last edition of Lamarck's Conchology, does not recognize its generic value, but describes Deluc's species (tom. vii. p. 68) under the designation Pinna Saussurei; the materials at his disposal seem to have been very imperfect, and in consequence his description is incomplete and calculated to give an erroneous idea of its characteristic features. The term 'subrquivalvis' for instance does not accord with Deluc's figures ; it is stated to gape posteriorly, which, judging from our specimens, must be an error; the character of the terminal extremity and interior of the hinge-line are not mentioned. The only other recent notice of the genus which we have discovered is contained in the volume of Dr. Pictet, which is devoted to fossil conchology, where the figures of Deluc are copied on a reduced scale, but no additional information is given. From the absence of all notice of the genus by the learling systematic writers on concho$\operatorname{logy}$, it may be concluded that they did not recognize the distinction of Deluc's shell from Pinna, or having no personal knowledge of the form, they hesitated to allow it a place with recognized genera. It has therefore hitherto existed almost on 
the horizon of science as an obscure and problematical object, which it will be our present endeavour to bring more nearly within the grasp of the conchologist.

\section{Generic Character.}

Shell of fibrous structure, thick, ovate, oblong, inequivalve, inequilateral and irregular; umbones terminal, produced and funnel-shaped, the apex gaping. Hinge-margin oblique and elongated, the margins undulated, anterior margin corrugated and thickened beneath the umbones. Hinge lateral, linear and without teeth.

Our specimens, though not numerous, exemplify the genus in a satisfactory manner, and place its characters free from ambiguity. The valves are both separated and in apposition; in one instance the interior of the cardinal border and terminal extremity have been cleared, but the muscular impressions have not been seen. The general figure is oblique and nearly quadrilateral, one valve being convex, the other flattened or even a little concave; the margins undulate, are rather irregular, including even the hinge-line, and there is always a considerable undulation occupying the posterior border, at which part the valves are thinner, more expanded and flattened; the undulations of both valves correspond; they are rounded, having no posterior truncation, and when closed leave no hiatus. In the concavity of the anterior border is a corrugation which marks the probable place of exit for a byssus, a feature exactly corresponding with that in Perna, Avicula, \&c., but there is scarcely any distinct hiatus perceptible. The umbones form a hollow funnel-shaped cavity narrowing to the extremity, but open, the opening being rounded, and formed by the termination of both the valves; the shell about its middle and anterior parts attains a thickness exceeding any recent bivalve, and comparable only with the fossil genus Catillus; the smaller valve is the thinnest. With respect to its affinities, that to Pinna, which has engaged the attention of naturalists, would appear, to say the least of it, to be very remote. What do we find in conformity with a delicate, almost papyraceous shell, straight, equivalve and regular, with a truncated, widely gaping posterior extremity? Absolutely nothing; on the contrary we have a shell of monstrous thickness, very oblique, inequivalve and irregular, its posterior side being neither truncated nor gaping-in fact nearly every generic feature of importance is reversed; the fibrous structure common to both seems to have misled observers into a supposed generic identity. But even the structure of the two genera when carefully examined presents a difference equally marked and characteristic : the strength of 
the thin and delicate Pinna is produced by a double structure, by its substance consisting of two layers, the outer being fibrous, the fibres placed perpendicular to the surface as in Trichites; but the inner one is nacreous or lamellar, a contrivance which effectually obviates the fragility which pertains to the fibrous structure. Trichites on the contrary has one structure throughout; the perpendicular fibres are crossed by a few extremely tine parallel laminæ, which do not break off the continuity of the fibres, and impede fracture only to a very limited extent. The genus Catillus, found only in the cretaceous rocks, is that which seems to approximate most nearly to the present form. Both have very much the same general figure, fibrous structure and thick substance; on the other hand, the Catilli are nearly equivalve and regular, the hinge consists internally of a linear series of crenulations, and the terminal character of the umbones is likewise distinct.

The position of Trichites in the conchological series should therefore be near to Catillus; its irregularity is such that no two of our specimens are exactly alike either in outline, convexity or surface. Two individuals were nearly covered with small adherent shells, a sufficient indication that their habits were sedentary or sluggish. The great fragility is certainly not the effect of fossilization, but a consequence of its structure, and must always have existed; the condition in which the shells are found presents a sufficient confirmation of this idea. After frequent and persevering, but for the most part fruitless exertions with the hammer and chisel, we are enabled to state that Trichites usually occurs in the state of distinct portions or fragments, and that entire individuals are rare; the fracture too not unfrequently is found across the thickest part of the test. A mollusk, whose shell was thus constituted, could scarcely have been the denizen of a shelly beach within the influence of the tide, or exposed to frequent rolling and collisions with other fragmentary bodies; its habitat must have been tranquil, and probably covered deeply and defended by soft mud or sand. Specimens which occur in the chaotic shelly beds of the Great Oolite, locally termed ' planking:' may be regarded as travelled, and, as might be anticipated, are usually in portions only, and these seldom large; individuals perfect or approaching to perfect are the exceptions to the rule. In the upper portion of the Inferior Oolite the conditions of seabottom appear to have been somewhat different; there is an absence of shelly detritus; the valves of the Conchifera are most frequently in apposition, and Trichites, as far as can be ascertained, appears more frequently to approach to the perfect condition. 
Example.

Trichites nodosus. Plate X.

(Great and Inferior Oolite.)

Shell quadrately curved, with longitudinal waved nodose ribs; ribs few, diverging, some bifid. The larger valve convex, the lesser rather concave, with nodules nearly obsolete, disposed in two concentric series.

Our specimens differ much in the degree of convexity and character of the ribs, the latter being occasionally scarcely distinguishable; the terminal umbones are very much curved and turned forwards. The planking beds of the Great Oolite at Minchinhampton Common and freestone of the Inferior Oolite near to the same locality produce it, but it has not been recognized in the upper portion of the Inferior Oolite; from the intractable character of that rock, however, this circumstance must not be considered as conclusive of its absence. Our examples in point of size convey but a very inadequate notion of the magnitude often attained by the genus; but it would appear that the larger sections belong to the second, or possibly even to a third and more gigantic species. The Pinna Saussurei (Pinnegene of Deluc) is distinct from our Cotteswold shells; his figures, taken from specimens broken and partly enveloped in the stone, do not convey any precise idea of the external form, but the portion which exhibits the character of the surface is altogether different.

Trichites undatus.

\section{(Inferior Oolite.)}

Shell oblong ; umbones ... . ; ribs obscure, few, concentric, irregular and undulated, sometimes obsolete in the larger valve. The smaller valve unknown.

Length 9 inches, breadth $7 \frac{1}{2}$ inches.

The only well-preserved example in our possession has lost the terminal extremity, but in other respects is nearly perfect; the hinge-line is more nearly horizontal than in the T. nodosus, and the entire form is less convex ; the other valve, though attached, cannot be cleared from the hard matrix. It occurs abundantly in the upper ragstone of the Inferior Oolite, a rock which usually defies all attempts to separate the shell in a tolerable condition ; in this instance a large portion of the surface fortunately coincided with the natural parting of the bed. 
Ann. Mag.Nat. Hist. S.2.Vol.V.P1 X.
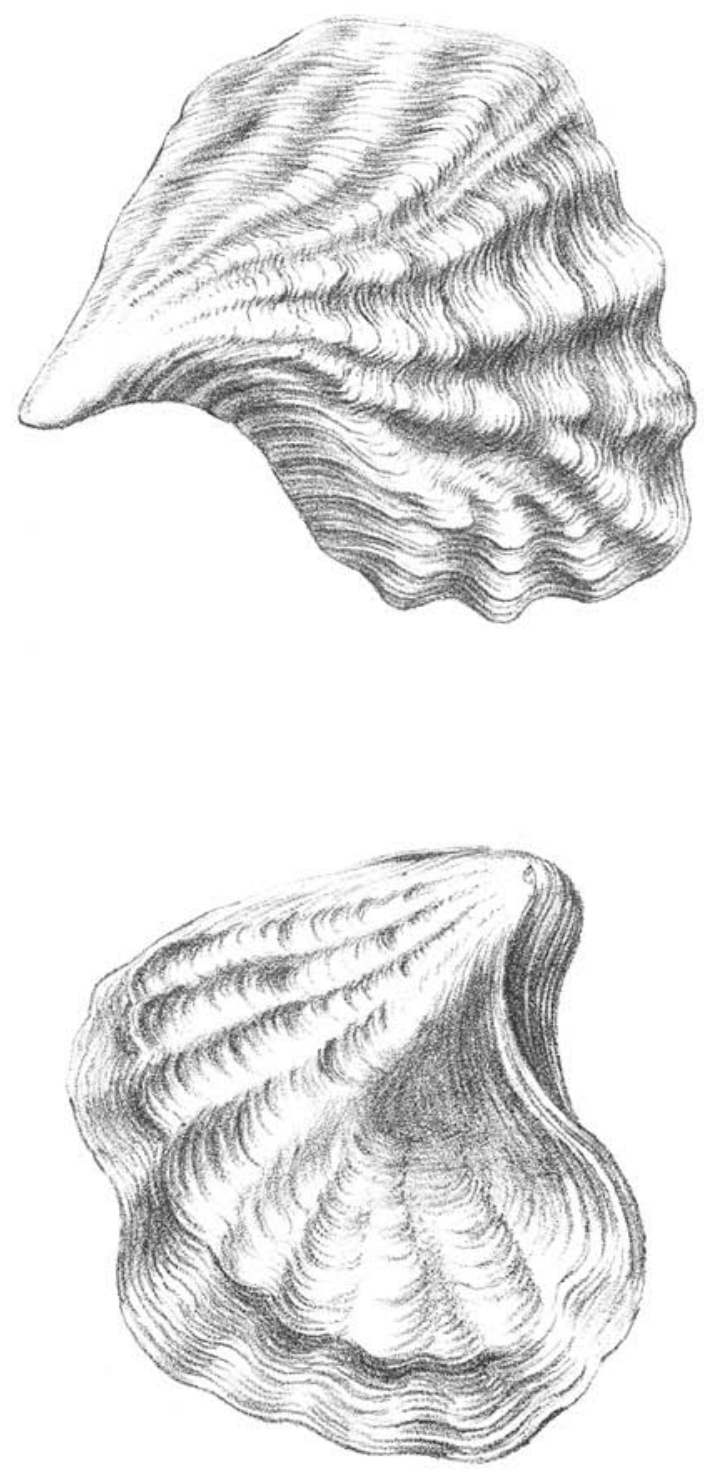

- Lycett ded

J.De G. Sowerby in lap del. 